\title{
Acceleration and Deceleration Rates of Various Vehicle Categories at Signalized Intersections in Mixed Traffic Conditions
}

\author{
Sushmitha Ramireddy ${ }^{1 *}$, Vineethreddy Ala¹, Ravishankar KVR ${ }^{1}$, Arpan Mehar ${ }^{1}$ \\ ${ }^{1}$ Department of Civil Engineering, National Institute of Technology, 506004 Warangal, Telangana, India \\ * Corresponding author, e-mail: susmitharamireddy@gmail.com
}

Received: 06 July 2020, Accepted: 07 August 2020, Published online: 08 December 2021

\begin{abstract}
The acceleration and deceleration rates vary from one vehicle type to another. The same vehicle type also exhibits variations in acceleration and deceleration rates due to vast variation in their dynamic and physical characteristics, ratio between weight and power, driver behaviour during acceleration and deceleration manoeuvres. Accurate estimation of acceleration and deceleration rates is very important for proper signal design to ensure minimum control delay for vehicles, which are passing through the intersection. The present study measures acceleration and deceleration rates for four vehicle categories: Two-wheeler, Three-wheeler, Car, and Light Commercial Vehicle (LCV), by using Open Street Map (OSM) tracker mobile application. The acceleration and deceleration rates were measured at 24 signalized intersection approaches in Hyderabad and Warangal cities. The study also developed acceleration and deceleration models for each vehicle type and the developed models were validated based on field data. The results showed that the predicted acceleration and deceleration models showed close relation with those measured in the field. The developed models are useful in predicting average acceleration and deceleration rate for different vehicle types under mixed and poor lane disciplined traffic conditions.
\end{abstract}

Keywords

acceleration rate, deceleration rate, vehicle types, OSM tracker, mixed traffic

\section{Introduction}

The acceleration and deceleration rates of vehicles play a crucial role in the design of length of amber time, length of acceleration zone, length of deceleration zone, estimation of start-up lost times, estimation of rate of fuel consumption, estimation of control delay, length of turn bays, estimation of vehicle emissions etc. (El-Shawarby et al., 2007; Bokare and Maurya, 2017). The acceleration and deceleration rates of vehicles also influence the Level of Service (LOS) and capacity of signalized intersections (Bogdanović et al., 2013). The inaccurate acceleration and deceleration rates of vehicles result in inaccurate determination of capacity and level of service of signalized intersections. The inaccurate estimation of acceleration and deceleration times leads to inaccurate estimation of control delay for the intersection, because control delay is the sum of acceleration time, stopped time and deceleration time. This study measures acceleration and deceleration rates for various vehicle categories in the field by using mobile application and models were developed for predicting acceleration and deceleration rates for various driving conditions. Researchers in the past studies measured acceleration and decelerations rates using Global Positioning System (GPS) (Bokare and Maurya, 2017), video recording technique (Bogdanović et al., 2013), floating car method (Brooks, 2012) and Metropia mobile application (Zhu et al., 2013). In the present study, a simple mobile application, namely the OSM tracker is used for measurement of acceleration and deceleration rates of various vehicle types at approaches of signalized intersections. The OSM tracker can track the accurate time to position of vehicles along with the deceleration and acceleration rates. In the present study, the OSM tracker data was matched with the real time video recorded data to check its accuracy and validity. This application enables easy extraction of field information. In one of the past studies, Jamulla and Ravishankar (2019) demonstrated the 
application of OSM tracker for collecting travel time data on a corridor. This mobile application provides information of latitude, longitude, time interval and speed.

The present study is intended to check the applicability of OSM tracker mobile application in measuring acceleration and deceleration rates under mixed traffic conditions. Also, it promises to contribute linear models for four different vehicle types, for estimating acceleration and deceleration rates by considering travel speed as an independent variable. The organization of the present paper is as follows: Section 2 outlines the review of earlier studies about acceleration and deceleration rate measurement and modelling. Section 3 illustrates the study area selection. The data collection and extraction procedure are described in Section 4. Linear models developed for acceleration and deceleration rate are described in Section 5. Section 6 describes the validation of developed linear models. The conclusions and future scope are summarized in Section 7.

\section{Literature review}

In the past research work, researchers focused on measuring acceleration and deceleration characteristics (speed, time and length) and some other studies were focussed on predicting driver behaviour during acceleration and deceleration manoeuvre. Long (2000) studied the acceleration behaviour of starting vehicles in queue. A linear model was developed for finding vehicle acceleration rate. The linear acceleration model showed excellent performance in predicting acceleration rates of starting vehicles. The average acceleration value of a passenger car was found to be $1.44 \mathrm{~m} / \mathrm{s}^{2}$ when speed was in a range from 0 to $40.3 \mathrm{~km} / \mathrm{h}$. Akcelik and Besley (2001) developed acceleration and deceleration models to define acceleration and deceleration rates at signalized intersections. The acceleration distance, deceleration distance, acceleration rate, deceleration rate and their corresponding time were found using relations given by SIDRA 2. The mean acceleration rate, acceleration distance, acceleration time and maximum rate of acceleration were found to be $1.53 \mathrm{~m} / \mathrm{s}^{2}, 106.4 \mathrm{~m}, 10.9 \mathrm{~s}$ and $2.69 \mathrm{~m} / \mathrm{s}^{2}$, respectively. The mean deceleration rate, deceleration distance, deceleration time and maximum rate of deceleration were found to be $-1.78 \mathrm{~m} / \mathrm{s}^{2}, 88.5 \mathrm{~m}, 9.4 \mathrm{~s}$ and $-3.09 \mathrm{~m} / \mathrm{s}^{2}$, respectively. El-Shawarby et al. (2007) studied the deceleration behaviour of drivers at signalized intersections in USA. The observed deceleration rate of drivers was found to be in a range of $7.47 \mathrm{~m} / \mathrm{s}^{2}$ and $1.51 \mathrm{~m} / \mathrm{s}^{2}$. The average deceleration rate was observed to be in a range of $2.2 \mathrm{~m} / \mathrm{s}^{2}$ and
$5.9 \mathrm{~m} / \mathrm{s}^{2}$ in a period of 1.6 seconds and 5.6 seconds. The study results showed that the deceleration rates exhibited by female drivers were slightly lower than that of male drivers. Drivers of age groups of younger than 40 years and older than 60 years were found to be driven their vehicles with higher deceleration rates compared to the drivers of age group of 40 to 59 years. Minh et al. (2007) proposed models for estimating acceleration and deceleration rates of motorcycles at signalized intersections in Southeast Asia. Probability density models were developed to find acceleration and deceleration rates of motorcycles. Also, a relation was developed between lane width of motorcycles and motorcycle speed. The developed models were found to be useful in evaluating acceleration and deceleration rates of motorcycles.

Boonsiripant et al. (2010) proposed a methodology for finding the lengths of acceleration and deceleration zones at signalized intersections using GPS data in Georgia, USA. For speed limits of $30,35,40$ and $45 \mathrm{~km} / \mathrm{h}$, the lengths of the acceleration zones were found to be 486, 636, 685 and 819 feet, respectively. The length of the deceleration zones was found to be 520, 652, 704 and 778 feet for corresponding speed limits of 30, 35, 40 and $45 \mathrm{~km} / \mathrm{h}$. The study results indicated that the lengths of acceleration and deceleration zones were found to be less than those specified by American Society of State Highway and Transportation Officials (AASHTO) standards. Brooks (2012) conducted a study on acceleration elements of vehicles in Pennsylvania in rural areas, using floating car technique. Time-distance, velocity-acceleration, and time-velocity models were developed. The passing sight distance of $195 \mathrm{~m}$ is recommended at a design speed of $35 \mathrm{~km} / \mathrm{h}$. Maurya and Bokare (2012) conducted a study on deceleration behaviour of various vehicle categories under heterogeneous traffic conditions. Various deceleration models were developed based on speed, for various vehicle types: truck, three-wheeler, two-wheeler, and car. The observed deceleration rates for two wheelers, three wheelers, cars and trucks were found to be $1.59,1.16,1.71$ and $0.88 \mathrm{~m} / \mathrm{s}^{2}$, respectively. The observed maximum deceleration rates were found to be lower than those proposed by AASHTO.

Bogdanović et al. (2013) measured acceleration rates of vehicles using video recorded data at signalized intersections in Southeast Europe in Novi Sad, Serbia. The study proposed a new methodology for measuring acceleration rates. The maximum acceleration rate values of starting vehicles were found to be in a range of 1.8 to $2.0 \mathrm{~m} / \mathrm{s}^{2}$. The acceleration rates of the following vehicles were found to 
be in a range of 1.7 to $1.9 \mathrm{~m} / \mathrm{s}^{2}$. It was also found that, the acceleration values were found to follow normal distribution. Zhu et al. (2013) measured the pattern of driver behaviour at signalized intersections in United States of America using 'Metropia' smart phone mobile application. 'Metropia' app gives speed, deceleration and acceleration rates corresponding to each coordinate point. The average speed observed on freeways and local roads was $61.54 \mathrm{mph}$ and $44.13 \mathrm{mph}$, respectively. The accelerations and decelerations of the drivers were observed to be in a range of $0.39 \mathrm{~m} / \mathrm{s}^{2}$ to $-0.30 \mathrm{~m} / \mathrm{s}^{2}$.

Bokare and Maurya (2016) studied the behaviour of acceleration for three wheelers under heterogeneous traffic conditions in India. It was found that the measured acceleration rates for three wheelers varied from those reported in the literature. Various acceleration models were proposed based on observed speed of vehicles at the intersection. The acceleration rate observed for two wheelers varied from $1.009 \mathrm{~m} / \mathrm{s}^{2}$ to $0.50 \mathrm{~m} / \mathrm{s}^{2}$ with an acceleration time of 3 to 6 seconds. Bokare and Maurya (2017) studied the acceleration and deceleration behaviour for various vehicle categories using Global Positioning System (GPS) data. The speed at maximum acceleration rate and the time taken to attain maximum acceleration were presented for different vehicle categories. The maximum acceleration rate for truck, three-wheeler, two-wheeler, diesel car and petrol car were found to be $1.0,0.64,1.96,2.23$, and $2.87 \mathrm{~m} / \mathrm{s}^{2}$, respectively. Different models were proposed based on speed to study the acceleration/deceleration behaviour of different vehicle categories. Omar et al. (2018) studied acceleration and deceleration characteristics of vehicles on a dangerous route FT050 in Johor. GPS data was used to record speed profiles of various vehicles. From the

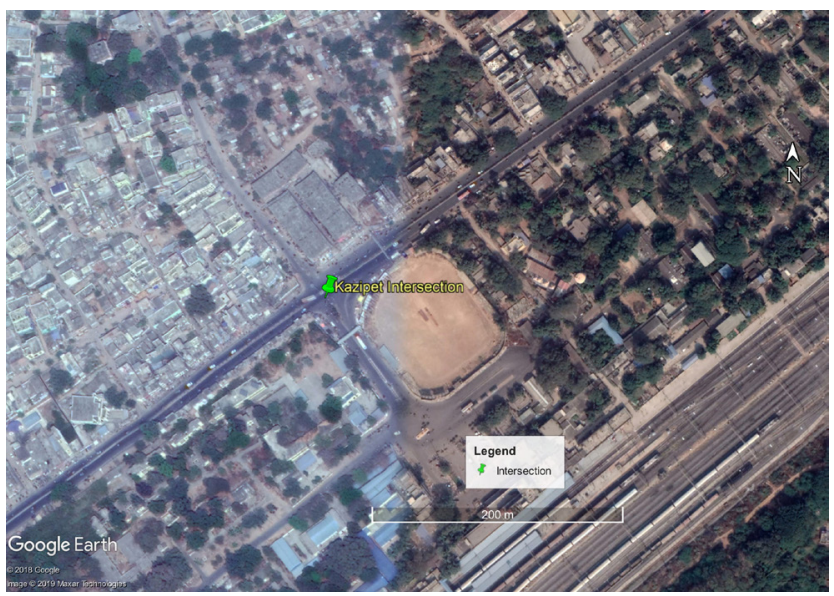

(a) acceleration/deceleration profiles obtained from GPS data, it was found that almost $30-50 \%$ of the drivers were driving in a dangerous position.

In the past research work, researchers measured acceleration and deceleration rates for different vehicle types. Also, various models were developed for predicting acceleration and deceleration rates at approaches of signalized intersections. Many of the research works were reported for homogeneous traffic conditions where lane discipline existed. A limited number of research works were conducted under mixed traffic conditions. Also, the OSM tracker mobile application was not used in the previous research for measuring acceleration and deceleration rates. The present study aims to develop acceleration and deceleration models for four vehicle categories: two-wheelers, three-wheelers, cars (standard car and big utility car) and LCVs. Also, the applicability of OSM tracker mobile application is checked for measuring acceleration and deceleration rates under mixed traffic conditions.

\section{Study area}

For the present study, the acceleration and deceleration rates were measured for 24 approaches of six signalized intersections in India: Kazipet (I-1), KU (I-2), Suchitra (I-3), Patny circle (I-4), Gandimaisamma (I-5) and Bachupally (I-6) intersections. I-1 and I-2 are in Warangal city, whereas I-3, I-4, I-5 and I-6 are in Hyderabad city. Each study intersection is a four-legged intersection with allowed traffic movement in through, right, and left turns. The study intersections are chosen in such a way that, there is no metro rail and flyover passing over the intersection. The satellite maps of the study intersections chosen from Warangal city and Hyderabad city are shown in Figs. 1 and 2, respectively.

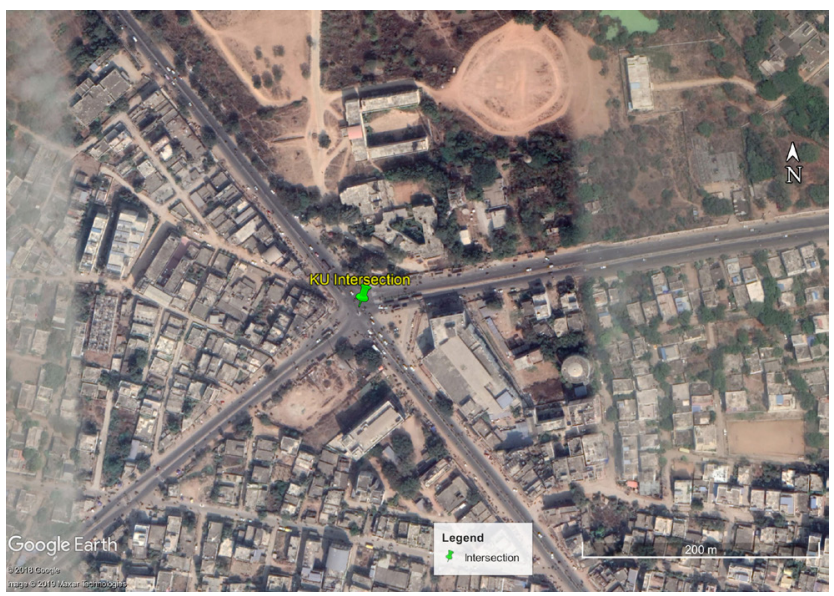

(b)

Fig. 1 (a) Satellite image of study intersections at Kazipet in Warangal city, (b) Satellite image of study intersection at Kakatiya Univeristy in Warangal city 


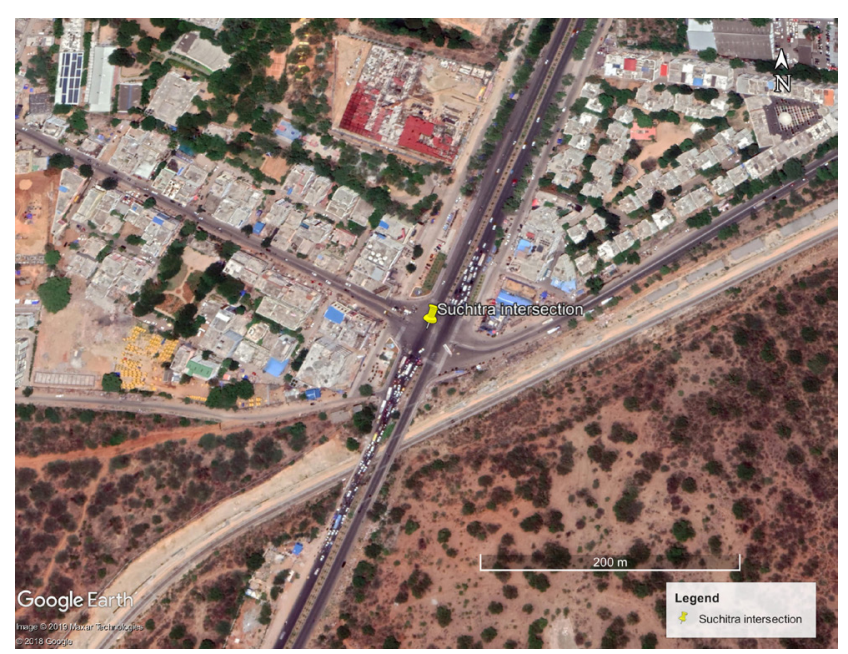

(a)

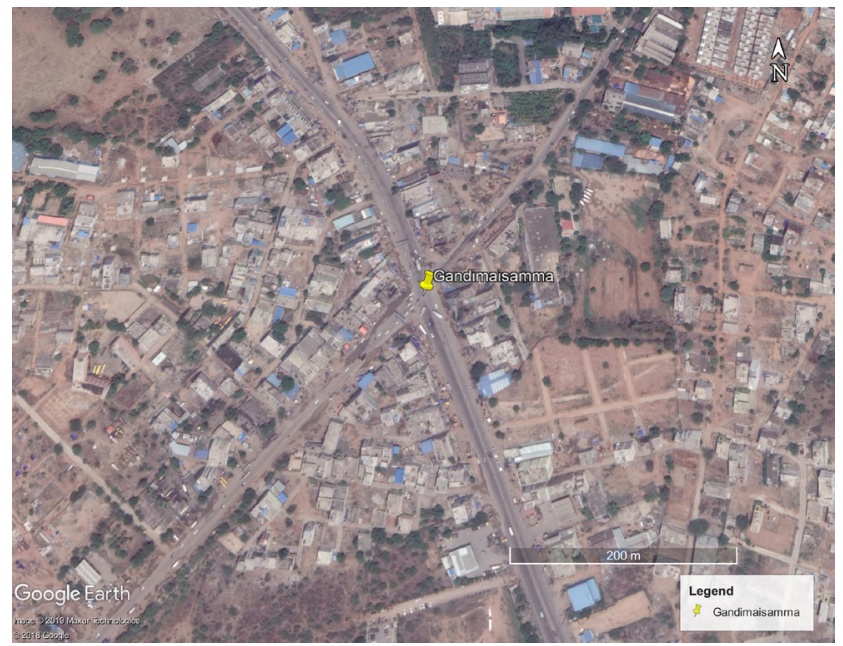

(c)

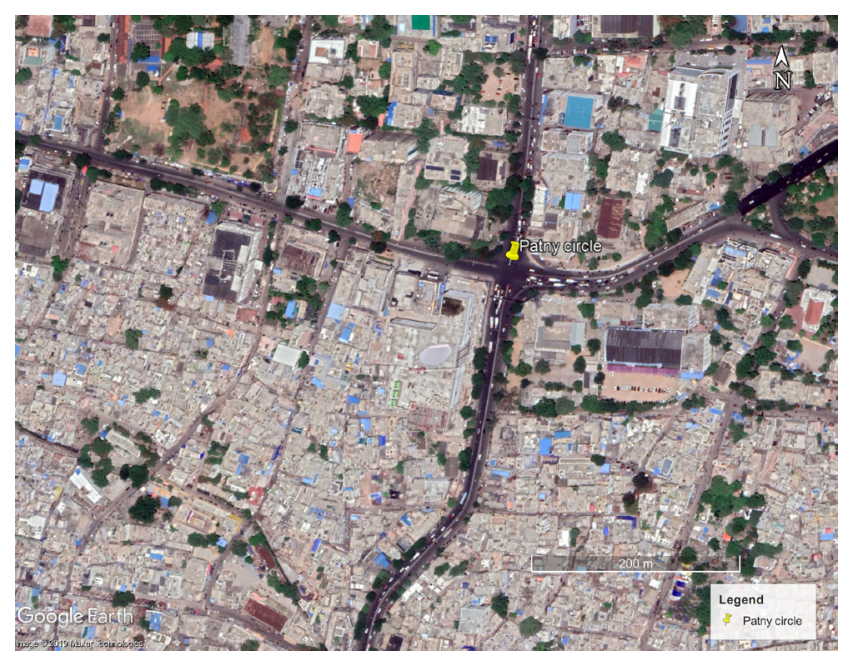

(b)

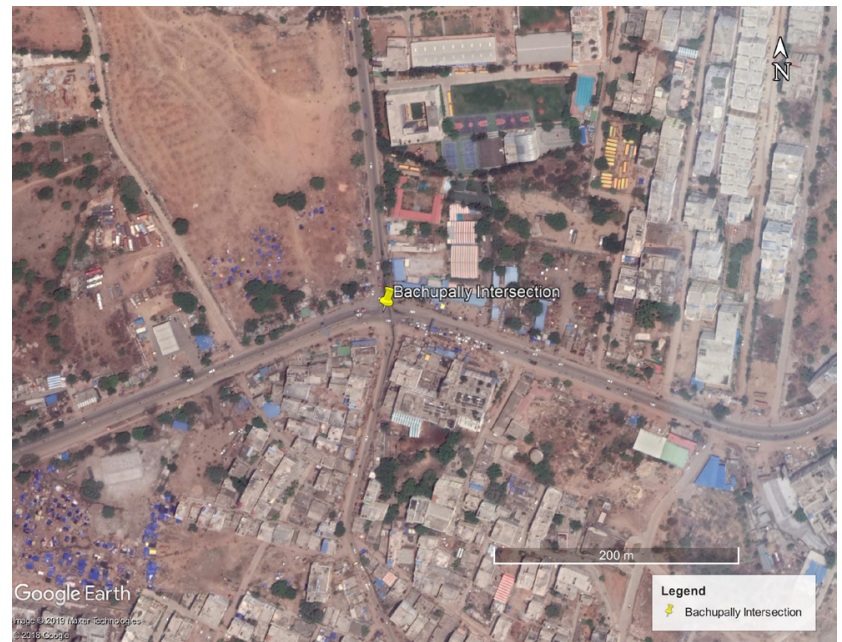

(d)

Fig. 2 (a) Satellite image of study intersections at Suchitra in Hyderabad city, (b) Satellite image of study intersections at Patny circle in Hyderabad city, (c) Satellite image of study intersections at Gandimaisamma in Hyderabad city, (d) Satellite image of study intersections at Bachupally in Hyderabad city

All the study intersections were operating with four phase signal systems and with the provision of free left movements on all the four approaches of the intersections.

\section{Data collection and extraction}

For the present research work, data collection is done using both OSM tracker mobile application and video recording technique. The OSM tracker mobile application records latitude, longitude, speed (mph), distance (m) and time (seconds) corresponding to each coordinate point throughout the run. The acceleration and deceleration times were noted down for four vehicle types: two-wheeler, threewheeler, car and LCV. More than 40 runs were made with each vehicle type at each approach on all the selected intersections i.e. for each approach a total of 160 runs were made with all vehicle types during peak hours. Each run was made by operating OSM tracker app and video recording was also done parallelly while moving with the stream. Each run showed both acceleration and deceleration times and distances. The run probably starts from the point before deceleration operation starts and ends after re-acceleration of the vehicle is attained. The average acceleration and deceleration rates, distances and time were extracted for each one second interval, for each vehicle type for each approach, from the data recorded by the OSM tracker and the OSM tracker data was cross checked with the data obtained from video recorded clips. The time of acceleration and deceleration as measured in the field by OSM tracker and video clips matched closely. The field extracted average acceleration rate and corresponding speed measured at different approaches are given for each vehicle type in Table 1. 
Table 1 Average acceleration rate and average speed of vehicle types

\begin{tabular}{|c|c|c|c|c|c|c|c|c|}
\hline \multirow{2}{*}{ Approach } & \multicolumn{4}{|c|}{ Average acceleration rate $\left(\mathrm{m} / \mathrm{s}^{2}\right)$} & \multicolumn{4}{|c|}{ Average speed during acceleration $(\mathrm{m} / \mathrm{s})$} \\
\hline & TW & $3 \mathrm{~W}$ & Car & $\mathrm{LCV}$ & TW & $3 \mathrm{~W}$ & Car & $\mathrm{LCV}$ \\
\hline NB-1 & 0.555 & 0.404 & 0.554 & 0.491 & 5.930 & 4.570 & 8.098 & 5.342 \\
\hline SB-1 & 0.444 & 0.436 & 0.440 & 0.522 & 2.346 & 4.130 & 4.324 & 5.302 \\
\hline EB-1 & 0.519 & 0.354 & 0.495 & 0.483 & 3.158 & 2.304 & 5.015 & 4.897 \\
\hline WB-1 & 0.606 & 0.390 & 0.639 & 0.547 & 7.567 & 3.140 & 8.790 & 5.897 \\
\hline NB-2 & 0.542 & 0.416 & 0.444 & 0.457 & 5.664 & 4.031 & 4.879 & 3.634 \\
\hline SB-2 & 0.663 & 0.501 & 0.523 & 0.500 & 7.065 & 3.789 & 4.890 & 6.215 \\
\hline EB-2 & 0.455 & 0.466 & 0.347 & 0.450 & 1.971 & 4.560 & 2.879 & 4.678 \\
\hline WB-2 & 0.531 & 0.365 & 0.418 & 0.390 & 4.456 & 3.130 & 3.545 & 1.280 \\
\hline NB-3 & 0.650 & 0.387 & 0.410 & 0.470 & 5.678 & 3.420 & 2.987 & 4.908 \\
\hline SB-3 & 0.840 & 0.470 & 0.490 & 0.480 & 9.174 & 5.346 & 4.834 & 6.789 \\
\hline EB-3 & 0.700 & 0.410 & 0.403 & 0.490 & 8.381 & 3.290 & 3.077 & 5.234 \\
\hline WB-3 & 0.710 & 0.440 & 0.500 & 0.470 & 7.775 & 3.356 & 6.098 & 5.980 \\
\hline NB-4 & 0.700 & 0.418 & 0.550 & 0.449 & 7.765 & 3.134 & 7.789 & 3.151 \\
\hline SB-4 & 0.660 & 0.486 & 0.440 & 0.405 & 7.036 & 4.356 & 4.099 & 3.670 \\
\hline EB-4 & 0.627 & 0.485 & 0.370 & 0.486 & 5.677 & 4.567 & 3.420 & 5.890 \\
\hline WB-4 & 0.535 & 0.552 & 0.493 & 0.436 & 4.386 & 7.568 & 5.098 & 3.675 \\
\hline NB-5 & 0.578 & 0.432 & 0.568 & 0.476 & 6.423 & 3.567 & 7.854 & 3.875 \\
\hline SB-5 & 0.657 & 0.378 & 0.489 & 0.406 & 6.435 & 3.132 & 5.346 & 2.976 \\
\hline EB-5 & 0.713 & 0.502 & 0.582 & 0.492 & 8.765 & 6.984 & 7.543 & 5.324 \\
\hline WB-5 & 0.564 & 0.452 & 0.463 & 0.503 & 5.879 & 5.213 & 4.536 & 5.463 \\
\hline NB-6 & 0.576 & 0.386 & 0.555 & 0.420 & 7.154 & 3.260 & 6.595 & 3.234 \\
\hline SB-6 & 0.531 & 0.350 & 0.502 & 0.410 & 3.158 & 4.780 & 4.879 & 2.888 \\
\hline EB-6 & 0.554 & 0.400 & 0.541 & 0.430 & 6.456 & 3.940 & 5.567 & 4.126 \\
\hline WB-6 & 0.468 & 0.371 & 0.423 & 0.400 & 2.584 & 2.450 & 3.570 & 1.530 \\
\hline
\end{tabular}

Each average acceleration rate and average speed as given in Table 1 is the average of 40 samples (runs). The average acceleration rate $\left(\mathrm{m} / \mathrm{s}^{2}\right)$ for two wheelers, three wheelers, cars and LCV as determined at intersection approaches are observed to be $0.599 \mathrm{~m} / \mathrm{s}^{2}, 0.427 \mathrm{~m} / \mathrm{s}^{2}, 0.485 \mathrm{~m} / \mathrm{s}^{2}, 0.461 \mathrm{~m} /$ $\mathrm{s}^{2}$, respectively. The average speed $(\mathrm{m} / \mathrm{s})$ for two wheelers, three wheelers, cars and LCV as determined, at intersection approaches are observed to be $5.87 \mathrm{~m} / \mathrm{s}, 4.084 \mathrm{~m} / \mathrm{s}, 5.238 \mathrm{~m} / \mathrm{s}$ and $4.415 \mathrm{~m} / \mathrm{s}$, respectively. The field extracted average deceleration rate and corresponding speed measured at different approaches are given for each vehicle type in Table 2.

Each average deceleration rate and average speed value in Table 2 is the average of 40 samples (runs). The average deceleration rate $\left(\mathrm{m} / \mathrm{s}^{2}\right)$ for two wheelers, three wheelers, cars and LCV as determined, at intersection approaches are observed to be $0.554 \mathrm{~m} / \mathrm{s}^{2}, 0.586 \mathrm{~m} / \mathrm{s}^{2}, 0.624 \mathrm{~m} / \mathrm{s}^{2}, 0.776 \mathrm{~m} / \mathrm{s}^{2}$ respectively. The average speed $(\mathrm{m} / \mathrm{s})$ for two wheelers, three wheelers, cars and LCV as determined, at intersection approaches are observed to be $4.66 \mathrm{~m} / \mathrm{s}, 4.67 \mathrm{~m} / \mathrm{s}, 4.41 \mathrm{~m} / \mathrm{s}$ and $5.27 \mathrm{~m} / \mathrm{s}$, respectively.

\section{The maximum average acceleration, deceleration rates and the travel speed}

The maximum average acceleration, deceleration rates of selected vehicle categories and their corresponding travel speed were analysed at each intersection and are presented in Table 3.

From the observed acceleration and deceleration rates, it is clear that, the acceleration rate of two wheelers and cars is high compared to that of three wheelers and LCVs. The reason is that, two wheelers and cars have higher acceleration capability due to their high horse power, static and dynamic characteristics. Also, the deceleration rate of LCVs is high compared to three wheelers, cars and two wheelers. The deceleration distance is observed to be same for all vehicle types, for a given approach. As the weight to power ratio of LCVs is relatively higher as compared to other vehicle types, the deceleration rate of LCVs is observed to be higher compared to other vehicle types. 
Table 2 Average deceleration rate and average speed of vehicle types

\begin{tabular}{|c|c|c|c|c|c|c|c|c|}
\hline \multirow{2}{*}{ Approach } & \multicolumn{4}{|c|}{ Avg. deceleration rate $\left(\mathrm{m} / \mathrm{s}^{2}\right)$} & \multicolumn{4}{|c|}{ Avg. speed during deceleration $(\mathrm{m} / \mathrm{s})$} \\
\hline & TW & $3 \mathrm{~W}$ & Car & $\mathrm{LCV}$ & TW & $3 \mathrm{~W}$ & Car & $\mathrm{LCV}$ \\
\hline NB-1 & 0.44 & 0.364 & 0.452 & 0.656 & 8.978 & 6.260 & 5.110 & 4.360 \\
\hline SB-1 & 0.51 & 0.699 & 0.678 & 0.715 & 6.481 & 3.245 & 3.714 & 5.680 \\
\hline EB-1 & 0.439 & 0.523 & 0.75 & 0.946 & 8.453 & 5.770 & 5.346 & 3.634 \\
\hline WB-1 & 0.515 & 0.602 & 0.782 & 1.003 & 6.097 & 4.657 & 2.400 & 2.678 \\
\hline NB-2 & 0.688 & 0.515 & 0.759 & 0.659 & 4.614 & 5.302 & 4.160 & 5.130 \\
\hline SB-2 & 0.452 & 0.517 & 0.369 & 0.755 & 7.284 & 10.063 & 6.750 & 4.353 \\
\hline EB-2 & 0.645 & 0.471 & 0.634 & 0.87 & 4.742 & 4.260 & 5.000 & 3.409 \\
\hline WB-2 & 0.381 & 0.491 & 0.357 & 0.635 & 8.914 & 6.650 & 8.620 & 6.613 \\
\hline NB-3 & 0.539 & 0.505 & 0.602 & 0.759 & 4.710 & 6.890 & 4.960 & 7.078 \\
\hline SB-3 & 0.529 & 0.496 & 0.547 & 0.895 & 2.828 & 6.129 & 5.980 & 8.740 \\
\hline EB-3 & 0.675 & 0.632 & 0.59 & 0.719 & 3.325 & 2.267 & 5.840 & 8.240 \\
\hline WB-3 & 0.565 & 0.529 & 0.847 & 0.768 & 1.610 & 4.260 & 2.139 & 7.530 \\
\hline NB-4 & 0.643 & 0.578 & 0.586 & 0.67 & 3.270 & 4.236 & 5.940 & 5.895 \\
\hline SB-4 & 0.632 & 0.594 & 0.703 & 0.836 & 4.060 & 2.054 & 3.040 & 4.705 \\
\hline EB-4 & 0.657 & 0.558 & 0.413 & 0.795 & 4.737 & 3.654 & 5.150 & 3.208 \\
\hline WB-4 & 0.687 & 0.800 & 0.539 & 0.772 & 4.012 & 4.356 & 6.000 & 4.286 \\
\hline NB-5 & 0.496 & 0.743 & 0.698 & 0.798 & 1.067 & 2.678 & 3.456 & 6.785 \\
\hline SB-5 & 0.499 & 0.729 & 0.71 & 0.762 & 2.056 & 2.415 & 3.213 & 4.213 \\
\hline EB-5 & 0.543 & 0.786 & 0.604 & 0.754 & 1.113 & 5.367 & 5.132 & 5.897 \\
\hline WB-5 & 0.587 & 0.675 & 0.776 & 0.798 & 1.145 & 5.324 & 2.234 & 5.901 \\
\hline NB-6 & 0.564 & 0.546 & 0.632 & 0.713 & 5.456 & 3.620 & 3.272 & 6.954 \\
\hline SB-6 & 0.517 & 0.548 & 0.656 & 0.795 & 6.741 & 4.678 & 2.280 & 3.125 \\
\hline EB-6 & 0.567 & 0.562 & 0.637 & 0.843 & 5.625 & 4.056 & 4.850 & 3.678 \\
\hline WB-6 & 0.532 & 0.610 & 0.675 & 0.724 & 4.549 & 3.789 & 1.150 & 4.456 \\
\hline
\end{tabular}

Table 3 The maximum average acceleration rate, deceleration rate and corresponding travel speed

\begin{tabular}{|c|c|c|c|c|c|c|c|c|c|c|c|c|c|c|c|c|}
\hline \multirow[t]{2}{*}{$\begin{array}{l}\text { Inter- } \\
\text { section }\end{array}$} & \multicolumn{4}{|c|}{$\begin{array}{c}\text { Maximum avg. acceleration } \\
\text { rate }\left(\mathrm{m} / \mathrm{s}^{2}\right)\end{array}$} & \multicolumn{4}{|c|}{$\begin{array}{l}\text { Maximum avg. travel speed } \\
(\mathrm{m} / \mathrm{s}) \text { (corresponding to } \\
\text { acceleration) }\end{array}$} & \multicolumn{4}{|c|}{$\begin{array}{l}\text { Maximum avg. deceleration } \\
\text { rate }\left(\mathrm{m} / \mathrm{s}^{2}\right)\end{array}$} & \multicolumn{4}{|c|}{$\begin{array}{l}\text { Maximum avg. travel speed } \\
(\mathrm{m} / \mathrm{s}) \text { (corresponding to } \\
\text { deceleration) }\end{array}$} \\
\hline & TW & $3 \mathrm{~W}$ & Car & LCV & TW & $3 \mathrm{~W}$ & Car & LCV & TW & $3 \mathrm{~W}$ & Car & LCV & TW & $3 \mathrm{~W}$ & Car & $\mathrm{LCV}$ \\
\hline I-1 & 0.53 & 0.40 & 0.53 & 0.51 & 4.75 & 3.54 & 6.56 & 5.36 & 0.48 & 0.55 & 0.66 & 0.83 & 7.50 & 4.98 & 4.14 & 4.08 \\
\hline $\mathrm{I}-2$ & 0.55 & 0.44 & 0.43 & 0.45 & 4.79 & 3.87 & 4.05 & 3.95 & 0.54 & 0.50 & 0.53 & 0.73 & 6.39 & 6.57 & 6.13 & 4.88 \\
\hline $\mathrm{I}-3$ & 0.73 & 0.43 & 0.45 & 0.48 & 7.75 & 3.85 & 4.25 & 5.73 & 0.58 & 0.54 & 0.65 & 0.78 & 3.12 & 4.89 & 4.73 & 7.89 \\
\hline I-4 & 0.63 & 0.49 & 0.46 & 0.44 & 6.22 & 4.91 & 5.11 & 4.09 & 0.65 & 0.63 & 0.56 & 0.77 & 4.02 & 3.57 & 5.03 & 4.52 \\
\hline I-5 & 0.63 & 0.44 & 0.53 & 0.47 & 6.87 & 4.73 & 6.32 & 4.41 & 0.53 & 0.73 & 0.70 & 0.78 & 1.35 & 3.95 & 3.51 & 5.70 \\
\hline I-6 & 0.53 & 0.38 & 0.51 & 0.42 & 4.84 & 3.61 & 5.15 & 2.95 & 0.55 & 0.56 & 0.65 & 0.77 & 5.59 & 4.04 & 2.89 & 4.55 \\
\hline
\end{tabular}

\section{Acceleration and deceleration models}

The relationship between acceleration rate/deceleration rate with average travel speed are examined which is observed to be a linear one. Correlation analysis performed between acceleration rate/deceleration rate and speed have showed a good correlation between them.

Furthermore, acceleration and deceleration linear models are developed for the vehicle types selected in the study.

\subsection{Acceleration model for signalized intersection approach}

Out of six intersections (24 approaches), data collected at four (16 approaches) intersections (I-1, I-3, I-5 and I-6) is used for model development and the remaining (I-2 and I-4) is used for model validation. The coefficients of linear acceleration models along with the statistical data are given in Table 4 , where, $A_{i}=$ acceleration rate $\left(\mathrm{m} / \mathrm{s}^{2}\right)$ of vehicle 
category $i, V_{i}=$ speed $(\mathrm{m} / \mathrm{s})$ of vehicle category $i$ during acceleration manoeuvre. The $p$-value and $t$-critical value of the variables are $<0.05$ and $>1.96$ at $5 \%$ significance level.

\subsection{Deceleration model for signalized intersection approach}

Out of six intersections (24 approaches), data collected at four (16 approaches) intersections (I-1, I-3, I-5 and I-6) is used for model development and the remaining (I-2 and I-4) is used for model validation. The coefficients of linear deceleration models along with the statistical data are given in Table 5, where, $D_{i}=$ deceleration rate $\left(\mathrm{m} / \mathrm{s}^{2}\right)$ of vehicle category $i, V_{i}=$ speed $(\mathrm{m} / \mathrm{s})$ of vehicle category $i$ during deceleration manoeuvre. The $p$-value and $t$-critical value of the variables are $<0.05$ and $>1.96$ at $5 \%$ significance level.

\section{Validation}

In the present study, field data collected from eight approaches of two different signalized intersections are used for validation of the models. The Relative Percent Error (RPE), Maximum Absolute Percentage Error (MAPE) and Index of Agreement (IA) are used as measures for model validation. A value of IA close to 1 is said to be a good prediction and a value of IA close to zero is said to be a poor prediction. The general form of RPE, MAPE and IA is shown by Eqs. (1-3), respectively.

$$
\begin{aligned}
& \mathrm{RPE}=\left(\frac{y_{\text {obs }}-y_{\text {pred }}}{y_{\text {obs }}}\right) \times 100, \\
& \mathrm{MAPE}=\frac{1}{N} \sum\left|\frac{y_{\text {obs }}-y_{\text {pred }}}{y_{\text {obs }}}\right| \times 100, \\
& \mathrm{IA}=1-\left[\frac{\sum\left(y_{\text {obs }}-y_{\text {pred }}\right)^{2}}{\sum\left(\left(\left|y_{\text {obs }}-\overline{y_{\text {obs }}}\right|\right)+\left(\left|y_{\text {pred }}-\overline{y_{\text {pred }}}\right|\right)\right)^{2}}\right],
\end{aligned}
$$

where, $y_{o b s}=$ field observed data (acceleration and deceleration rate $\left.\left(\mathrm{m} / \mathrm{s}^{2}\right)\right), y_{\text {pred }}=$ predicted data (acceleration and deceleration rate $\left.\left(\mathrm{m} / \mathrm{s}^{2}\right)\right), N=$ number of observations. The accuracy and error measures of acceleration models are presented in Table 6.

The RPE, MAPE values of the acceleration models developed are lower and IA values are close to 1 . Therefore, there is a good prediction of acceleration rate, with the developed acceleration models. The accuracy and error

\begin{tabular}{|c|c|c|c|c|c|c|c|c|}
\hline \multirow{2}{*}{ Vehicle type } & \multirow{2}{*}{$\begin{array}{c}\text { Model } \\
A_{i}=a+b V_{i} \\
a\end{array}$} & \multirow{2}{*}{$\begin{array}{l}\mathrm{R}^{2} \\
B \\
\end{array}$} & \multicolumn{2}{|c|}{ Standard error } & \multicolumn{2}{|c|}{$p$-values } & \multicolumn{2}{|c|}{$t$-values } \\
\hline & & & & & $A$ & $V_{i}$ & $A$ & $V_{i}$ \\
\hline Two wheeler & 0.344 & 0.044 & 0.850 & 0.042 & 0.000 & 0.000 & 10.816 & 8.806 \\
\hline Three wheeler & 0.291 & 0.035 & 0.650 & 0.032 & 0.000 & 0.000 & 9.903 & 5.125 \\
\hline Car & 0.280 & 0.038 & 0.860 & 0.029 & 0.000 & 0.000 & 13.051 & 9.392 \\
\hline $\mathrm{LCV}$ & 0.312 & 0.035 & 0.677 & 0.044 & 0.000 & 0.000 & 8.777 & 5.423 \\
\hline
\end{tabular}
measures of deceleration models are presented in Table 7.

Table 4 Acceleration models for each vehicle category

\begin{tabular}{|c|c|c|c|c|c|c|c|c|}
\hline \multirow{2}{*}{ Vehicle type } & \multirow{2}{*}{$\begin{array}{c}\text { Model } \\
D_{i}=a+b V_{i} \\
a\end{array}$} & \multirow{2}{*}{$\begin{array}{l}\mathrm{R}^{2} \\
B \\
\end{array}$} & \multicolumn{2}{|c|}{ Standard error } & \multicolumn{2}{|c|}{$p$-values } & \multicolumn{2}{|c|}{$t$-values } \\
\hline & & & & & $A$ & $V_{i}$ & $A$ & $V_{i}$ \\
\hline Two wheeler & 1.077 & -0.079 & 0.893 & 0.064 & 0.000 & 0.000 & 25.688 & -10.820 \\
\hline Three wheeler & 0.756 & -0.045 & 0.499 & 0.093 & 0.000 & 0.002 & 11.657 & -3.734 \\
\hline Car & 0.970 & -0.073 & 0.664 & 0.089 & 0.000 & 0.000 & 13.177 & -5.270 \\
\hline LCV & 1.152 & -0.084 & 0.836 & 0.072 & 0.000 & 0.000 & 20.560 & -8.464 \\
\hline
\end{tabular}

Table 5 Deceleration models for each vehicle category

\begin{tabular}{|c|c|c|c|c|}
\hline Accuracy and/ Error measure & Two-wheeler & Three-wheeler & Car & LCV \\
\hline \multirow[t]{2}{*}{ RPE } & Minimum-1.605 & Minimum-2.202 & Minimum-1.152 & Minimum-1.110 \\
\hline & Maximum-15.621 & Maximum-12.180 & Maximum-9.100 & Maximum-13.11 \\
\hline MAPE & 8.095 & 8.961 & 3.786 & 4.582 \\
\hline IA & 0.875 & 0.753 & 0.885 & 0.888 \\
\hline
\end{tabular}

Table 6 Accuracy and error measures of acceleration models for various vehicle types 
Table 7 Accuracy and error measures of deceleration models for various vehicle types

\begin{tabular}{|c|c|c|c|c|c|c|c|c|c|}
\hline \multicolumn{2}{|l|}{$\begin{array}{l}\text { Accuracy and/ Error } \\
\text { measure }\end{array}$} & \multicolumn{2}{|c|}{$\begin{array}{l}\text { Validation of deceleration } \\
\text { model for two-wheeler }\end{array}$} & \multicolumn{2}{|c|}{$\begin{array}{l}\text { Validation of deceleration } \\
\text { model for three-wheeler }\end{array}$} & \multicolumn{2}{|c|}{$\begin{array}{l}\text { Validation of deceleration } \\
\text { model for car }\end{array}$} & \multicolumn{2}{|c|}{$\begin{array}{l}\text { Validation of deceleration } \\
\text { model for LCV }\end{array}$} \\
\hline \multirow[t]{2}{*}{ RPE } & & \multicolumn{2}{|l|}{ Minimum- 0.265} & \multicolumn{2}{|c|}{ Minimum-0.614 } & \multicolumn{2}{|c|}{ Minimum-0.976 } & \multicolumn{2}{|c|}{ Minimum-3.361 } \\
\hline & & \multicolumn{2}{|l|}{ Maximum-10.83 } & \multicolumn{2}{|c|}{ Maximum-13.20 } & \multicolumn{2}{|c|}{ Maximum-7.313 } & \multicolumn{2}{|c|}{ Maximum-10.86 } \\
\hline MAPE & & \multicolumn{2}{|l|}{4.994} & \multicolumn{2}{|r|}{5.126} & \multicolumn{2}{|r|}{3.724} & \multicolumn{2}{|c|}{6.295} \\
\hline \multicolumn{2}{|l|}{ IA } & \multicolumn{2}{|l|}{0.935} & \multicolumn{2}{|r|}{0.767} & \multicolumn{2}{|r|}{0.971} & \multicolumn{2}{|c|}{0.900} \\
\hline \multirow[t]{2}{*}{ Study } & \multicolumn{2}{|c|}{ Two wheeler } & \multicolumn{3}{|c|}{ Three wheeler } & \multicolumn{2}{|c|}{ Car } & \multicolumn{2}{|c|}{$\mathrm{LCV}$} \\
\hline & $\begin{array}{l}\text { Average } \\
\text { acceleration } \\
\text { rate }\left(\mathrm{m} / \mathrm{s}^{2}\right)\end{array}$ & $\begin{array}{c}\text { Average } \\
\text { deceleration } \\
\text { rate }\left(\mathrm{m} / \mathrm{s}^{2}\right)\end{array}$ & $\begin{array}{r}\mathrm{Av} \\
\text { accel } \\
\text { rate }\end{array}$ & $\begin{array}{l}\text { rage } \\
\text { eration } \\
\left(\mathrm{m} / \mathrm{s}^{2}\right)\end{array}$ & $\begin{array}{c}\text { Average } \\
\text { deceleration } \\
\text { rate }\left(\mathrm{m} / \mathrm{s}^{2}\right)\end{array}$ & $\begin{array}{c}\text { Average } \\
\text { acceleration } \\
\text { rate }\left(\mathrm{m} / \mathrm{s}^{2}\right)\end{array}$ & $\begin{array}{c}\text { Average } \\
\text { deceleration } \\
\text { rate }\left(\mathrm{m} / \mathrm{s}^{2}\right)\end{array}$ & $\begin{array}{c}\text { Average } \\
\text { acceleration } \\
\text { rate }\left(\mathrm{m} / \mathrm{s}^{2}\right)\end{array}$ & $\begin{array}{c}\text { Average } \\
\text { deceleration } \\
\text { rate }\left(\mathrm{m} / \mathrm{s}^{2}\right)\end{array}$ \\
\hline $\begin{array}{c}\text { Bokare and } \\
\text { Maurya (2017) }\end{array}$ & 0.46 & 0.49 & & 21 & 0.35 & 0.51 & 2.51 & - & - \\
\hline Present study & 0.599 & 0.67 & & 427 & 0.538 & 0.485 & 0.640 & 0.460 & 0.681 \\
\hline
\end{tabular}

The RPE, MAPE values of the deceleration models developed are significantly lower and IA values are close to 1 . Therefore, there is a good prediction of deceleration rate, with the developed deceleration models in the present study.

\section{Discussion}

Only a few studies were based on mixed traffic conditions (Bokare and Maurya, 2017) at signalized intersections. In Section 8, the results of the present study are compared with the results obtained from the study conducted by Bokare and Maurya (2017) and are tabulated in Table 8.

Most of the acceleration and deceleration studies done in the previous research work were based on homogeneous traffic conditions.

The average acceleration and deceleration rate values of different vehicle categories obtained by Bokare and Maurya (2017) are lower than those obtained from the present study. The research work done under mixed traffic condition by Bokare and Maurya (2017) considered data from a single intersection from Nagpur city. More data could be considered for capturing variations in acceleration and deceleration behaviour of various vehicle types. The present study considered data from six intersections. This research work will be helpful in estimating realistic acceleration and deceleration values in urban intersections.

\section{Summary and conclusions}

In the present study, acceleration and deceleration rates are measured on approaches of six signalized intersections using OSMtrackermobileapplication. Thestudyapproaches are chosen form Warangal and Hyderabad cities in India. From the results of the study, it is observed that, the OSM tracker can be used as a good alternative for obtaining acceleration and deceleration of vehicles. The acceleration and deceleration rates were measured for four vehicle categories namely Two-wheeler, Three-wheeler, Car and LCV. The observed average acceleration rates for twowheeler, three-wheeler, car and LCV are obtained as 0.599 $\mathrm{m} / \mathrm{s}^{2}, 0.427 \mathrm{~m} / \mathrm{s}^{2}, 0.485 \mathrm{~m} / \mathrm{s}^{2}$ and $0.461 \mathrm{~m} / \mathrm{s}^{2}$, respectively. The observed average speed values for two-wheeler, threewheeler, car and LCV are obtained as $5.87 \mathrm{~m} / \mathrm{s}, 4.084 \mathrm{~m} / \mathrm{s}$, $5.238 \mathrm{~m} / \mathrm{s}$ and $4.415 \mathrm{~m} / \mathrm{s}$, respectively. It may be concluded that, the average acceleration at given speed of vehicle type Two-wheeler and Car is found to be higher as compared to that of vehicle types Three-wheeler and LCV. The static and dynamic characteristics of two wheelers and cars promote higher acceleration capability compared to three wheelers and LCV. Similarly, the observed average deceleration obtained for vehicle type Two-wheeler, Three-wheeler, Car and LCV are found to be $0.554 \mathrm{~m} / \mathrm{s}^{2}$, $0.586 \mathrm{~m} / \mathrm{s}^{2}, 0.624 \mathrm{~m} / \mathrm{s}^{2}$ and $0.776 \mathrm{~m} / \mathrm{s}^{2}$, respectively. The average speed on which the deceleration rates are obtained as $4.66 \mathrm{~m} / \mathrm{s}, 4.67 \mathrm{~m} / \mathrm{s}, 4.41 \mathrm{~m} / \mathrm{s}$ and $5.27 \mathrm{~m} / \mathrm{s}$ for twowheeler, three-wheeler, car and LCV, respectively. It may be concluded that the deceleration rate of LCV is observed to be higher compared to the other three vehicle categories. Vehicle type LCV generally takes relatively more time to decelerate and, therefore, it starts decelerating well in advance before approaching to the signalized intersection during red time. The other vehicle categories i.e., two wheelers, three wheelers and cars are having almost similar deceleration rates. The reason is that all the three vehicle categories tend to decelerate from the same point in the stretch, which was observed from the field. 
In the present study, acceleration and deceleration rate models are developed for four vehicle categories under mixed traffic conditions. The correlation analysis showed good relation between the acceleration rate/ deceleration rate and speed. Linear models are developed for estimating acceleration rate and deceleration rate by considering average travel speed as independent variable. The developed models are validated, using field data, on basis of RPE and MAPE. The errors obtained between predicted and observed values are found to be lower, which shows successful validation of developed models. This exact prediction of acceleration and deceleration rates helps in signal design (Bokare and Maurya, 2016).

\section{References}

Akcelik, R., Besley, M. (2001) "Acceleration and deceleration models", In: 23rd Conference of Australian Institutes of Transport Research (CAITR 2001), Melbourne, Australia, pp. 1-9.

Bogdanović, V., Ruškić, N., Papić, Z., Simeunović, M. (2013) "The Research of Vehicle Acceleration at Signalized Intersections", PROMET Traffic and Transportation, 25(1), pp. 33-42. https://doi.org/10.7307/ptt.v25i1.1245

Bokare, P. S., Maurya, A. K. (2016) "Study of Acceleration Behaviour of Motorized Three Wheeler in India", Transportation Research Procedia, 17, pp. 244-252. https://doi.org/10.1016/j.trpro.2016.11.088

Bokare, P. S., Maurya, A. K. (2017) "Acceleration-Deceleration of Various Vehicle Types", Transportation Research Procedia, 25, pp. 4733-4749. https://doi.org/10.1016/j.trpro.2017.05.486

Boonsiripant, S., Hunter, M., Dixon, K., Rodgers, M. O. (2010) "Measurement and Comparison of Acceleration and Deceleration Zones at Traffic Control Intersections", Journal of the Transportation Research Board, 2171(1), pp. 1-10. https://doi.org/10.3141/2171-01

Brooks, R. M. (2012) "Acceleration characteristics of vehicles in rural Pennsylvania", International Journal of Recent Research and Applied Sciences, 12(3), pp. 449-453.

El-Shawarby, I., Rakha, H., Inman, V. W., Davis, G. W. (2007) "Evaluation of Driver Deceleration Behaviour at Signalized Intersections", Transportation Research Record: Journal of the Transportation Research Board, 2018(1), pp. 29-35.

https://doi.org/10.3141/2018-05
The study can be extended by further considering a greater number of approaches to capture actual field conditions, so that the accuracy of the developed models could be increased. Also, the study can be extended by considering the effect of pedestrians on crosswalk during acceleration and deceleration of vehicles while negotiating with signalized intersection.

\section{Acknowledgments}

Authors are thankful to Ministry of Human Resources and Development (MHRD), Government of India, for providing research assistance.

Jamulla, J. K., Ravishankar, K.V.R. (2019) "An Innovative Method of Travel Time Data Collection Using Mobile GPS Application", International Journal of Transportation Engineering and Traffic System, 5(1), pp. 42-50.

Long, G. (2000) "Acceleration Characteristics of Starting Vehicles", Transportation Research Record: Journal of the Transportation Research Board, 1737(1), pp. 58-70.

https://doi.org/10.3141/1737-08

Maurya, A. K. Bokare, P. S. (2012) "Study of Deceleration Behaviour of Different Vehicle Types", International Journal for Traffic and Transport Engineering, 2(3), pp. 253-270. https://doi.org/10.7708/ijtte.2012.2(3).07

Minh, C. C., Sano, K., Cao, N. Y. (2007) "Acceleration and Deceleration Models of Motorcycles at Signalized Intersections", Journal of Eastern Asia Society for Transportation Studies, 7, pp. 2396-2411.

Omar, N., Prasetijo, J., Daniel, B. D., Abdullah, M. A. E., Ismail, I. (2018) "Study of Car Acceleration and Deceleration Characteristics at Dangerous Route FT050", IOP conference series: Earth and Environmental Science, 140, Article number: 012078. https://doi.org/10.1088/1755-1315/140/1/012078

Zhu, X., Hu, X., Chiu, Y.-C. (2013) "Design of Driving Behaviour Pattern Measurements Using Smartphone Global Positioning System Data", International Journal of Transportation Science and Technology, 2(4), pp. 269-288. https://doi.org/10.1260/2046-0430.2.4.269 